\title{
Saudi Reforms: Developing Tourism to minimize dependency on oil and its impact in the society
}

\author{
By \\ Dr Masood Ahmed \\ Asst. Professor \\ Department of Business Administration, \\ College of Business Administration, Jazan University, KSA \\ maahmed@jazanu.edu.sa, dr.ahmed.masood@gmail.com
}

\begin{abstract}
:
Many countries are raising questions on the intentions behind Saudi reforms. The low oil prices in 2008-09 were the awakening call for Saudis, and later in 2014, it became the reason to look for the economy that is less dependent on oil. The article studies the initiated social reforms and social impact of foreign cultural activities. It scrutinizes the Saudi social fabric under the social exchange theory and looks for the positive and negative effects of cultural exchanges. The paper also considers the COVID-19 situation in KSA as it has broken the chain of cultural events planned all over the country to promote tourism and improve the image of KSA.
\end{abstract}

Key Words: Employment, Governance Indicators, Oil Economy, Reforms, Welfare

JEL: 010, P46, Q01, R23, 


\section{Introduction:}

The world as the observant, Saudi Arabia, is reforming itself. Many countries are raising questions on the intentions behind reforms and are scrutinizing each step minutely. Rationally speaking Saudis are not compelled to reform, they can carry the same economic and social life for many more years, and the world does not have enough bargaining power against the oil-rich country. Any outside interference will create chaos over oil prices and put the friendly and fruitful relationship with the US at risk, which is not likely to happen. Than why KSA choose to have social and economic reforms. The answer is the realization that the low oil prices will play havoc to their trillion-dollar economy, and they can not sustain the standards in the absence of reasonable oil prices.

Secondly, the young generation is aware of the circumstances, resources and challenges that the country is facing today; they want to change the country's image. They are more demanding in utilizing the available means that can be utilized in a better way like providing better education, employment and health facilities. They want to grow-out from oil dependencies and like to contribute in other fields. The research evaluates the Vision 2030 document prepared by the Saudi Government and aggressively marketed as the growth plan for Saudi reforms to study its social influence.

\section{Literature Review:}

The research article evaluates the Saudi Government Vision 2030 document, which describes its future course of action and objectives set by the government to be achieved before the year 2030. To understand the reforms' social impactthe social exchange theory (Emerson, 1976) is beneficial in explaining the Saudi invitation to selected cultural themes and sporting events under the reforms. Further social representation theory (Moliner, 2012) where host society shares social knowledge towards the external visitors, its application in Saudi case include religious flavour where Islamic religious events of Haj and Umra is used to spread new social and religious reforms and create a new Saudi identity.

The paper felt the need to improve the scope of social representation as a tool for studying social impact. It supports socio-economic bonding by relating it with the economic direction where the dependency on oil revenue is inversely related to social reforms, considering that education, employment and gender equality directly contribute to economic growth. The present reforms will push for an increase in nonoil revenue and require substantial education, employment and fair gender representation hence have a significant social impact on the present society.

The paper considers Growth machine theory (Madrigal, 1995) a tool to evaluate a citizen response and acceptance of an event. Large scale acceptance will indicate a socially acceptable impact and incorporation of external influence in the local culture.

The paper also considers the world governance indicators proposed by (Kraay, 2018), and the KSA position. Secondly, the article evaluates the KSA position in world development indicators forwarded by the World Bank. The Saudi claims were substantiated by reforms initiated by the government and reported by the news media. The article evaluates Saudi reforms against its intention to move away from oil dependence and grow its economy in a broader way satisfying long term objective of full employment for Saudi citizens and self-dependence in critical areas. 


\section{Methodology:}

The research article is a secondary database analysis. The focus is on developing a structured framework to analyze the Saudi reforms' expected social impact under Vision 2030, its relationship with oil dependency, and how COVID-19 affects reforms.

The research begins with identifying the components of social impact, for the purpose three theories Social Exchange theory, Social Representation theory and Growth Machine theory is studied.

Social exchange theory is promoted by Homans (1958) under theories of social behaviour, where social exchange involves benefits to each party. It is explained as exchanging activity through social interaction, either tangible or intangible, and having reward or cost attached to the activity. Social and economic benefits differ fundamentally (Nunkoo, 2016), while economic benefits are contractual, while social benefits are voluntary and relate to future adaptation. Social benefits are also uncertain and depend on host absorbing all or part of an exchange.

Social exchange theory helps explain the role of cultural adaptation where general acceptance of values, financial benefits and satisfaction derives from the enhancement of social status by acceptance of guest offerings as a reward has a profound and longlasting impact on the host society. On the same note, cost includes the negative outcome of exchange where unwanted features enter a society that cost time, money and local values and leads to corrupt practices.

Social representation theory denotes the host society's ability to create and spread social knowledge of an external event or external visitors. The theory helps analyze how groups and individuals transform themselves during interaction and communicate their systems of knowledge, beliefs and opinions particular to a culture (Moliner, 2012).

Growth machine theory is vital to understand how large-scale social acceptance of an event brings positivity and calmness to minimum resistance (Zhang, 2014). In contrast, large opposing groups' presence requires restructuring policies to promote social exchanges between different parties.

During the comparative analysis of (Saudi Vision 2030) document, the Vision 2030 document is compared with the World Development Indicators of the World bank. The article stresses the Saudi Government's present position and steps taken towards the vision document's goals. As reported in the media, social and economic changes are assessed, and its repercussions are studied over the Saudi culture. The article highlights the need to support strategic reforms and its positive effect over other countries and the Muslim population. The article explores possible outcomes and how reforms are strategically crucial for economic development and global peace.

\section{The Social Impact of Saudi reforms:}

"If you do not like your image, stay away from the mirror" this no longer valid for the New Saudi Arabia as it implements social and economic reforms. Still, it is not easy to change an image meticulously built over a long period of a primitive society that believes in Islam's extreme view, but that is precisely present leadership in KSA is trying to achieve. Saudi Arabia is working hard to accept the challenges they face today and moderate its approach to solving them. 
Recently famous singer-artist Mariah Carey, Janet Jackson Andrea Bocelli and K-pop group Super Junior performance in Saudi Arabia create a sense of change in Saudi society. WWE Crown Jewel event that takes place include women wrestlers Natalya, and Lacey Evans mark a significant shift in how Saudi's view women.

Shows like "Bazzar" by Cirque du Soleil in Riyadh where Lauren Joy Harley plays the floating woman enjoyed by the vast spectators. Multiplexes now alluring people to relish movies is another step for people's freedom - not long before people enjoy movies in their home using a satellite dish or internet. Things are changing, and people with extremist views may be perturbed, and it is not easy for any government to control such hidden elements. It is more critical to evaluate the social impact of events. It is necessary to understand how foreign culture will affect the quality of life, challenge the prevailing meaning of subjective well being and generate social capital that incorporates foreign cultural elements.

The positive and negative changes the population will integrate due to foreign culture exposure will change their lives. Inclusion of social impact indicators encompasses three essentials: the impact on the quality of life, change in subjective well-being, and social capital development.

Quality of life represents the precise conditions in which a population lives, exposure to events denotes the higher quality of life brings in desire for improvement. Factors like the freedom to work and entertainment opportunities, accumulation of wealth and material things, and access to healthcare are few factors used to evaluate life quality.

On the other hand, subjective well-being is the state of mind and measurement of happiness, and it is quite possible that even with low quality of life, a person feels happy and satisfied. Subjective well-being is an essential factor to study in Saudi society as Islamic principles and laws control the country and under Islamic principles material well being is less important than the disciplinary character and highest form of moral upbringing. The high moral values and discipline in life leave little space for external influence for a pious saul.

On the contrary, young and restless populations seek means to combine worldly possessions in the background of Islamic education and look for a middle path where they are par with the rest of the world. The struggle between the population who believe in old and disciplined approach and the new and more resilient who wants to work hard to enjoy the lifestyle and seek happiness in proud possessions.

Thirdly, social capital development is required where social relationships improve understanding and trust between the community cultural exchanges. More interest and information an event promotes, more is the chances of its success, and fewer will be the number of unhappy clusters than the happy clusters (Growth Machine Theory). Ultimately it is the acceptance of an event by the society at large that signifies its success.

The Vision 2030, seeks to achieve positive social impact from its foreign cultural and sports events. The focus is on generating future economic benefits by creating employment opportunities, developing recreational facilities and infrastructure and stimulating demand for products related to living standards. Similarly, it provides more entertainment opportunities where people are engaged in many exciting activities. Another objective of organizing cultural events is to enhance the country's image as a 
tolerant and progressive one, where foreign cultural events are welcomed, and doors are opened for others to observe rich Saudi culture and heritage.

The Saudi authorities need to be aware of the cost of negative impact before permitting the events. It is the awareness of authorities that minimizes the negativity. Factors like damage to the natural environment, noise pollution, litter, rowdy behaviour, overcrowding and traffic congestion can be controlled by proper planning. However, long term impact may include an increase in the cost of living and an increase in crime rate requires an in-depth study of each social event and its impact over the society.

For Saudis, the progressive steps result from an ordinary youth's internal distress, and it is also an outcome of information available under current affairs, availability of choices to fulfil desires backed by adequate purchasing power.

Nevertheless, the opportunities are hiding, in the challenges and Saudis wants to gain from it by reducing oil dependency and develop an economy competitive enough to accept future challenges and efficiently utilize the existing resources. In his address, the Prince emphasis on Islamic constitution and moderation in its method of adaptation. The steps are for real, and the world is witnessing a push in social and economic reforms. November 2019 witnessed the first major economic shift when Aramco's public issue opens, turning the company into a global industrial conglomerate and transforming Public Investment Fund into the world's largest sovereign wealth fund.

\section{Is this the end of the oil economy?}

Saudi Arabia has the largest oil production capacity, with almost one-fifth of the oil reserves under its boundaries. For KSA oil shocks are the reason behind its rapid progress in 1973-74 oil prices increased by more than $200 \%$ during that time KSA's GDP also increase in almost the same ratio from SR 53,047 million riyals to 159,276 million riyals. During the second oil price shock 1978-79, KSA GDP increased by 38\%, when oil prices increase by $24 \%$. Later at the time of the Iraq war, KSA's GDP increased by $13 \%$, and in forth oil shock the surge in oil prices in 2003 till 2008 boost Saudi economy by almost $16.7 \%$, and during this, the Saudi economy reaches 1.7 trillion economic milestones (Algahtani, 2016).

The fifth oil shock was the eye-opener for Saudis in 2008-09, where oil prices drop by $38 \%$, causing a $21.8 \%$ decline in Saudi GDP numbers. Since then the Saudi growth story is facing hurdles and their dependency on oil proving to be costly as it comprises almost $80 \%$ of their export revenue and with ups and downs in the oil prices their economic planning also sufferers by the same rate. The rise in oil prices is the reason behind the employment figures. The Saudi population will benefit from rapid development and rise in their income, attract huge expatriates, provide various services, and contribute to the Saudi development story. The reverse is true when the oil prices start their decline, employment slows down, and the government realize the need for economic reforms that include developing industries other than oil industries (Tarek Tawfik Yousef Alkhateeb, 2017).

The World Bank expects the GDP growth to be over 2\% and Saudi plan is to increase non-oil exports percentage and increase revenue from the present SAR 163 billion to SAR 1 trillion- for this, the Public Investment Fund's Assets will go up from SAR 600 billion to over 7 trillion. The reforms expect to attract FDI from the current level of $3.8 \%$ to over $5.7 \%$ of GDP and Saudis aims to increase private sector contribution in 
the economy from the current $40 \%$ of the GDP value to get it past $65 \%$. (Saudi Vision 2030)

The government is facing a young and restless population with an unemployment rate of $11.6 \%$ (Saudi Vision 2030) which they like to reduce, through their National Labour Gateway (TAQAT) and by establishing sector council and intrusting them to create the necessary marketable skills and knowledge that will be in demand soon.

The belief that Saudis depend on expatriates population for their progress is partially true as it employs a vast population of expatriates (34.14 million WB data). On the other hand, the KSA approach is quite different from the top expat-friendly countries like Qatar, UAE, Kuwait, Jordan and Singapore. While UAE opens its market for the expatriate population and a friendly investment environment, KSA has not done so. KSA uses oil money to develop infrastructure with expatriates' help; they only employ doctors, technicians, engineers and university and school teachers, and low skill workers for manual labour. Present investment in human resources are ready to reap benefits, and their young generation is ready to take over. The government is systematically reducing expatriates number in the fields where they feel Saudi youth has garnered sufficient expertise.

Public sector reforms include a proposal to train government employees (approx.500,000) using distance learning to generate skills needed to boost productivity. It is an ambitious step as it will bring in accountability and promote best practices in the government sector.

The retail sector is another area where the government aims to increase Saudis employment. Currently, the sector employs 1.5 million workers, but only 0.3 million Saudis (Saudi Vision 2030) are working. The sector has a potential growth rate of more than $10 \%$, to exploit the potential, the government decided to limit jobs in mobile shops only for Saudis. Similarly, no more dentist visa for foreigners as a sufficient number of Saudi dentist is available, and in universities, the foreign staff is under scrutiny. Every year they are replaced by Saudi faculties who are joining after completing their education. In the education sector, visas are not readily available for non-PhDs as they are no longer required unless they belong to the technical field and justified by the management.

Government Nitaqat programme categorized companies based on the number of Saudis they employ, under it companies benefit when Saudis are sufficient in number and punished if Saudis are less than the prescribed limit. The private sector expatriate workers are sending their family back as the government decided to impose residency permit fees on expatriates family members, and since July 2017, it starts from SAR 100 per month per family member and will double with each coming year till 2020 when it reaches to its maximum level. The decision put a substantial economic burden on expatriates, and for many, it is unviable to keep their family members inside the Kingdom.

The government committed itself to increase women participation in the workforce and aims a modest increase from the present $22 \%$ to $30 \%$ (Saudi Vision 2030). The government decision to promote women in employment and forcing the private sector to open the door for them is now noticeable in the society where females are now working in malls and hospitality businesses. Issuing licenses to females and letting them drive is a welcome move appreciated and recognized worldwide, and even critics judge it as a significant initiative towards the more free and developing society. 
Recent annual Forbes list of Powerful Businesswomen in the middle east has three women from Saudi Arabia in the top five (Arabnews $-5^{\text {th }}$ Feb 2020), all three belongs to the financial sector, associated with banks and Saudi Share market. It is interesting to note that these ladies with degrees from the world-renowned institutes and years of experience belong to a country that recently permitted women to drive.

Saudi women's success proves education framework and promotion, including foreign education opportunities for deserving male and female candidates, is gratifying, and with reforms, expectations are soaring.

Saudis are reaping the benefit of oil and are fortunate enough to increase their average household income by $75 \%$ (MaKinsey \& Company Report, 2015) due to the sharp rise in oil prices during the 2003-2013 period. The period also saw the creation of 4.4 million jobs in which Saudis took 1.7 million jobs. Vision 2030 aims to achieve better results without depending on oil revenues, and its focus is on modernizing society without diluting the Islamic principles.

Today, the 1.8 billion Islamic followers or $24.1 \%$ of the total world Muslim population perform their prayers in the direction of Holy city Makkah situated in KSA. Before the oil riches, the religious pilgrimage was the primary source of income for the country, even today, it aims to increase the faithful visitor's number from 8 million to 30 million annually (Saudi Vision 2030).

Arab news reports that economists predict that Haj and Umra's revenue is expected to exceed $\$ 150$ billion by 2022 . The aim is to accommodate 30 million Haj pilgrims and Umra performers by the year 2030. It is also believed that the sector is ready to provide at least 100,000 jobs to Saudi citizens. The government initiative to develop infrastructure and tourist destination in other cities to take advantage of religious tourism and attract them to other places is of strategic importance.

The new approach is to promote tourism along with religious pilgrimage. It is spending money on the development of heritage sites, promoting rich and beautiful coastline of Farsan Island and other seashores in different cities and orchestrating various activities to promote tourism. The approach aims to attract foreigners, previously restricted to two holy cities, and now they are free to travel in other cities and spend money. Second, wealthy Saudi citizens who enjoy holidays in other countries can enjoy the same facilities, and amusement means in their own country, in both cases, it is an economic gain for the country.

\section{How various world indicators measure KSA?}

KSA is a peaceful country governed strongly by its ruler under the Islamic constitution. Islamic constitution promotes social harmony through the purity of human relationships, forbid illegal relationships between man and woman, consumption of drugs and alcohol, and putting severe punishment as a deterrent.

Severe punishment creates fear, and people abstain from such activities, it is useful as the crime rate is 0.8 per 100,000 persons, putting KSA in those few countries where criminal activities are minimum (Saudi Vision 2030).

Daniel Kaufmann et al. (2010) in his World Bank Policy Research paper developed Worldwide Governance Indicators (WGI), and it consists of six fundamental indicators of governance: Voice and Accountability, Political Stability and Absence of Violence/Terrorism, Government Effectiveness, Regulatory Quality, Rule of Law and 
Control of corruption. He provides a comparison of 213 country and territories and ranks each indicator and nations on a scale of 0 to 100 .

In 2018 (WGI), the top 50 countries/territories scored more than 430 points out of the total 600 at an average of 72, while countries that rank between 51 to 100 their average score come down to 50. KSA overall performance positioned it at $109^{\text {th }}$, with a score of $277 / 600$ at an average of 46. Two indicators in which it suffers most are Voice and accountability and Political stability and non-violence where it scores only 5.91 and 28.57. Rest of the indicators are under the acceptable limits and points to the excellent health of the country.

In the United Nations e-government survey 2018, KSA ranked $52^{\text {nd }}$ well above the largest democratic country like India (96), and now aiming to be in the top five countries. The Global Competitiveness Report 2018 published by World Economic Forum gives $39^{\text {th }}$ Rank to KSA, and World Bank's Logistic Performance Index put KSA at $55^{\text {th }}$ Rank (2018).

With its oil-rich resources, Saudi Arabia scores high on the rule of law, control over corruption and quality regulation, and results in an environment conducive to economic growth. It is already in top 20 economies ( $18^{\text {th }}$ with Nominal GDP: $\$ 782.48$ billion and GDP (PPP) equal to $\$ 1.86$ trillion). Recent reforms to introduce Value Added Tax (VAT) and progressive labour laws now aim to align the economy with the rest of the economically developed countries and increase the non-oil revenue.

\section{COVID-19 and Kingdom of Saudi Arabia}

As a centre of Islam, Saudi Arabia is always open for religious pilgrimage for all nationalities, due to epidemic, it is evident that it suffers enormously. Although the timely decision to suspend international and domestic pilgrimage and ban on international travel proves beneficial. Still, more than three lakhs are affected by the virus, and more than five thousand deaths show the level of deep suffering.

The huge expatriates' population living in close premises are more susceptible, in order to save living expenses they chose to share space with many and if one of them got affected it means the whole house of individual got affected and become a spreader. The government identified the cause and took action on such premises to control the epidemic, but the big cities are still the worst affected by it.

The government focus on citizens welfare is visible in its approach to develop health and education system. The Ministry of Health share from the total budget is $8.40 \%$ (Ministry of Health, 2019). The availability of 22.5 beds, 33.1 physicians and 58.2 nursing staff per 10,000 of the population shows government commitment towards their citizens. The developed health structure helps the government handle the epidemic and strict measures like lockdown, hefty fine on non-compliance of COVID guidelines, and a well-structured and informative campaign to create awareness because of less than six thousand deaths, from more than three lakh infections.

The economic cost of COVID-19 is huge, beside the production lost, and lost in revenue from the pilgrimage season and the low oil prices force authorities to apply emergency measures. The $15 \%$ VAT application on consumable items is one such measure. The availability of government wealth fund with fatty deposits is a blessing and government is using it wisely, by announcing various measures to fight COVID-19.

Why Saudi Arabia security, stability and reforms are important for the world? 
KSA is one of the few countries where the crime rate is low, despite this Saudi Arabian image suffers due to extremist ideology adopted and propagated by few. Government is making all efforts necessary to keep such elements under control and improve its image. The administration is on the right track as it opens its market for investment and promises them with secure internal environment and business-friendly policies.

Although regional turmoil the war in Yemen, sympathy for Muslim brothers suffering in many countries has a considerable impact on the social fabric and prepares the ground for extremist ideology to flourish, the government is effectively curbing antisocial elements and simultaneously showing concern for humanitarian issues and willingness to help the sufferers in resolving them. Government action is earning goodwill both internally and internationally, but to washout its negative image, it needs time and more shreds of evidence for successful implementation of its vision.

Saudi Arabia risk ratings in currency, banking and economics are currently low, but there is a possibility of change if the situation deteriorates. Most of the present export earnings are from oil, but the government has initiated reforms to lessen its dependency. Meantime availability of sizeable sovereign wealth fund provides safety for government expenditure without facing any fiscal challenge.

Saudi Arabian prominence on social welfare is appreciable as it takes the responsibility of health and education expenses. Nevertheless, citizens do have the option to avail private sector facilities according to their convenience and income-earnings.

\section{Conclusion:}

The need for reforms felt due to low oil price shocks, and roll out in Vision 2030. The government realization that present extravagant expenditure habits are only possible in the future if they have income sources other than oil and gas. A strong economy is an indicator of a strong nation, too much dependence on sovereign wealth fund in years of price shock will prove costly in future. Secondly, it is crucial to keep investing in the educational, health and defence sector for a better tomorrow.

The move to push economic reforms centred around tourism should be appreciated. The government move to welcome entertainment and adventure mixed cultural exchange could signal that as a centre of the Islamic world, they open the doors for others to see Saudi Arabian heritage and invite well-known artists to market their reforms. Being at the centre of the Islamic world with two holiest cities and annual pilgrimage Haj inviting millions of Muslims, the decision to develop tourism, where the Muslims around the world will not only convey the hospitality message of Saudi Arabia but also provide a boost to the economy is a strategic winner.

The social impact analysis of events is essential to determine the general population's acceptance level, identifying the negative impact and controlling them at the initial level is most important. Social exchange theory and Growth machine theory are essential research to identify the social impact of large scale event and development of clusters (happy or unhappy) as it will bring social changes either in the form of resistance if the unhappy clusters are more in comparison to happy one or support if the happy clusters are dominant in numbers.

The objective of reforms remains to increase economic activity, boost employment opportunities for Saudi citizens, and enhance living standards beside other economic 
benefits. Simultaneously, the government wants to avoid any increase in crime level, disruption of peaceful life and an increase in living costs. KSA is the Islamic centre, and Muslims worldwide observe the changes, and it will be a strategic blunder if the reforms are portrayed as a dilution in Islamic principles or surrendering to western influence.

The complexity of having religious society and Islamic centre, KSA needs to be extra vigilant and need to study even the minute changes in the society and requires careful planning to craft out events that bring the desired social outcome avoiding adverse outcomes.

The reforms and its associated promotional events hurt badly due to COVID-19. Since March 2020, there are 341,495 cases inside KSA and 5144 deaths. The decisions to stop international flights, strict application of curfew, heavy penalties for persons seen breaking social distancing rules and having sufficient medical infrastructure to support and counter the epidemic are why the government is now able to normalize the life.

The decisions during COVID-19 has a substantial economic cost attached to it. The economy suffers on various fronts. The hotel industry lost one full season of Ramzan (The holy month) and Haj, in which only a few thousand people are allowed to perform Haj instead of millions who comes from outside. All those business activities associated with annual pilgrimage also suffers deeply, as business needs to shut down due to lack of customers. Future social impact study should include the COVID period and how much influence of an event is remaining on the population that happens before COVID situation. The identification will help in continuation from the point, instead of starting the activity all over again.

\section{References}

Algahtani, G. J. (2016). The Effect of Oil Prices Shocks on Economic Activity in Saudi Arabia: Econometric Approach. International Journal of Business and Management, 11(8). doi:10.5539/ijbm.v11n8p124

Al-Harbi, S. S. (2015). The Influence of Media in Children's Language Development. Journal of Educational and Developmental Psychology. 
Colombo, A. (2015). How to evaluate cultural impacts of events? A model and methodology proposal. Scandinavian Journal of Hospitality and Tourism. doi:10.1080/15022250.2015.1114900

DAVID CLINGINGSMITH, A. I. (2009). ESTIMATING THE IMPACT OF THE HAJJ: RELIGION AND TOLERANCE IN ISLAM'S GLOBAL GATHERING. The Quarterly Journal of Economics.

Emerson, R. M. (1976). Social Exchange Theory. Annual Review of Sociology, 2, 335-362. Retrieved from http://www.communicationcache.com/uploads/1/0/8/8/10887248/social_excha nge_theory_-_1976.pdf

Garcia, F. L. (2009). Measuring the Impacts of Large Scale Cultural Events: A Literature Review. Liverpool City Council.

https://www.arabnews.com. (2020, Feb 05). Retrieved from Arab News: https://arab.news/2gymf

Irshad, H. (2011). Impacts of community events and festivals on rural places. Government of Alberta, Agriculture and Rural Division .

Kraay, D. K. (2018). Worldwide Governance Indicators. Retrieved from worldbank.org: https://info.worldbank.org/governance/wgi/

Madrigal, R. (1995). Residents' perceptions and the role of government. Annals of Tourism Research, 22(1), 86-102. Retrieved from https://doi.org/10.1016/0160-7383(94)00070-9

(2015, December). MaKinsey \& Company Report. Retrieved from makinsey.com: https://www.mckinsey.com/featured-insights/employment-andgrowth/moving-saudi-arabias-economy-beyond-oil

Martin Wallstam, D. I. (n.d.). Evaluating the social impacts of events: in search of unified indicators for effective policymaking. Journal of Policy Research in Tourism, Leisure and Events, 12(2), 122-141. doi:10.1080/19407963.2018.1515214

Ministry of Health, S. A. (2019). Government Publication. Retrieved from https://www.moh.gov.sa/en/Ministry/Statistics/book/Pages/default.aspx

Moliner, P. R. (2012). Social representation theory. In P. M.-C. Patrick Rateau, HANDBOOK OF THEORIES OF SOCIAL PSYCHOLOGY (pp. 477-497). London: Sage Publication ltd. Retrieved from https://lmsspada.kemdikbud.go.id/pluginfile.php/69497/mod_resource/content /3/Handbook\%20of\%20social\%20psychology.pdf

News, A. (2017). Hajj revenues poised to exceed $\$ 150$ bn by 2022. Arab News.

Nunkoo, R. (2016). Toward a More Comprehensive Use of Social Exchange Theory to Study Residents' Attitudes to Tourism. Procedia Economics and Finance, 588-596.

Pasanen, J. M. (2010). Economic and socio-cultural impacts of two leading cultural festivals of Savonlinna. Global events congress IV: festival \& events research: 
state of the art. Incorporating the 8th AEMR events Management Educators' Forum, Leeds, U.K.

Rice, K. S. (2006). Social Exchange Theory. In Social Forces. doi:DOI: 10.1007/0387-36921-X_3

Tarek Tawfik Yousef Alkhateeb, Z. A. (2017). Oil Revenue, Public Spending, Gross Domestic Product and Employment in Saudi Arabia. International Journal of Energy Economics and Policy, 7(6), 27-31. Retrieved from www.econjournals.com

Vision 2030. Kingdom of Saudi Arabia. (n.d.). Retrieved from vision2030.gov.sa

Whitford, C. A. (2007). Festival Attendance and the Development of Social Capital. Journal of Convention \& Event Tourism, 8(2). Retrieved from http://dx.doi.org/10.1300/J452v08n02_01

World Development Indicators . (2020). Retrieved from World Bank: http://datatopics.worldbank.org/world-development-indicators/

Zhang, S. (2014). Land-centered urban politics in transitional China - Can they be explained by Growth Machine Theory? CITIES, 41, 179-186. doi:http://dx.doi.org/10.1016/j.cities.2014.02.010 